\title{
Assessment of Surface Water Quality of Noyyal River Using Wasp Model
}

\author{
G. Mahalakshmi ${ }^{1}$, M. Kumar ${ }^{2}$ andT. Ramasamy ${ }^{3}$ \\ ${ }^{1 \& 3}$ PG Student, Department of Environmental Engineering, ${ }^{2}$ Assistant Professor, Department of Civil Engineering, \\ Government College of Technology, Coimbatore, Tamil Nadu, India \\ E-Mail: gmaha1995@gmail.com
}

\begin{abstract}
The Noyyal River is a tributary of river Cauvery has been one of the most predominant and important rivers of Tamil Nadu. Unfortunately, certain stretches of river Noyyal are polluted due to effluent discharge from the industries and domestic sewage. The effective water environmental management strategies required to be implemented in this river to upgrade the water quality and to ensure sustainable development in the region. The aim of this work was to provide a basis for water environmental management in process of making important decisions. In this study WASP (Water Quality Simulation Program) is used as a model to identify the processes that underlie river water quality problems in a basin. WASP was recommended by EPA used as water quality model. Simulated values of Nitrate $\left(\mathrm{NO}_{3}\right)$, Dissolved Oxygen (DO), Total Dissolved Solids (TDS), Alkalinity and pH demonstrated the accuracy of the model and despite a significant data shortage in the study area. WASP model was found to be an acceptable tool for the assessment of water quality.

Keywords: Water Quality, Water Environmental Management, WASP, Nitrate, DO, TDS, pH
\end{abstract}

\section{INTRODUCTION}

All civilizations originate near river banks. The emergence of civilization in the name of urbanization and industrialization has spoiled the river basins. Pollution of water resources as a result of industrial development is very much evident in the town of Tirupur in Tamil Nadu. During the heavy industrialization, many textile (dying and bleaching) industries came into being along the Noyyal River. The effluents from these industries were directly let into the river leading to heavy contamination of the water making it unfit for human consumption [1,2]. In Tirupur, the two most water and chemical consuming industries are bleaching and dyeing units in the textile production chain, let out virtually all the effluents into the Noyyal river which flows through the region. Noyyal river influences the water usability of downstream threatens human health and aquatic ecosystems and increases competition for water. Due to industrialization, soil and groundwater resources in Noyyal river basin are contaminated to a great extent.

Many tools can be used for planning studies. One of these tools is mathematical modeling. Mathematical simulation models have been consulted to solve the water pollution problem in a river basin in recent years [3]. The simulation models indicate the values of water quality variable given the flow, the quantity and quality of the waste loadings andwaste discharges or to increase the waste assimilation capacity of the receiving systems [4].

WASP(The water quality analysis simulation program) is developed by the environmental protection bureau environment research laboratory in the United States nation, can use to imitate hydrology dynamics, river one dimension unsteady flow, lake and river mouth 3D unsteady to flow, normal regulations pollutant(include to fuse oxygen, living creature oxygen consumption and nourishment material and seaweed pollution) and poisonous pollutant(include organic chemistry material, metal and deposition thing the migration and conversion regulation in the water.Three main functions of the WASP fluid matter model are described the fluid matter present condition, provide a general fluid matter estimate and provide particular position fluid matter estimate. In this study, the model considers the stream as a one-dimensional channel with the steady flow and the water quality of the polluted segment the river is the comprehensive application of water quality model WASP and evaluates the performance of the model.

\section{SOURCE OF POLLUTION}

The main source of pollution is the bleaching and dyeing industries in Tirupur area. The semi-treated or without treated effluent from these industries are released into Noyyal river. In Tirupur, there are about 750 dyeing industries and bleaching industries are present. The effluents released by these units are stored in Orathupalayam dam. Noyyal water leads to serious changes in the physio-chemical characteristics of surface water[5].

\section{MATERIAL AND METHODS}

\section{A. Study Area and Sample Sites}

The River Noyyal is a sacred river in Tamil history. It originates from the hills of Velliangiri, in Western Ghats of Tamilnadu. It runs through Coimbatore, Tirupur, Erode and Karur districts in Tamilnadu. It flows over a length of $180 \mathrm{kms}$ and covers $3,510 \mathrm{sq}$. $\mathrm{km}$ area. The river basin boundary is between $10^{\circ} 54^{\prime} 00^{\prime \prime}$ to $11^{\circ} 19^{\prime} 03^{\prime \prime} \mathrm{N}$ and $76^{\circ}$ $39^{\prime} 30^{\prime \prime}$ to $77^{\circ} 05^{\prime} 25^{\prime \prime E}$. Several tanks located in and around Coimbatore and Tirupur cities, the river supplies water. In recent times, unprecedented nutrient enrichment of water bodies causing eutrophication, increased rate of sedimentation, loss of water storage capacity, lowered 
retention period and deteriorated water quality leads to mismanagement of surrounding areas of water bodies [6]. Due to the continuous, uncontrolled and partially treated discharge of effluent from dyeing and bleaching industries and untreated domestic sewage, it has been polluted. This has also spoiled the groundwater adjacent to the river.

The entire river ecosystem has been damaged in Orathupalayam dam region due to semi- treated effluent discharge into the river. The surface water, groundwater, soil and land have been degraded and no agricultural activity takes place here. On the basis of hydrological and ecological conditions, Noyyal river has been classified into five (5) segments that are Sulur (S1), Samalapuram (S2), Mangalam (S3), Andipalyam (S4), Orathupalayam (S5).

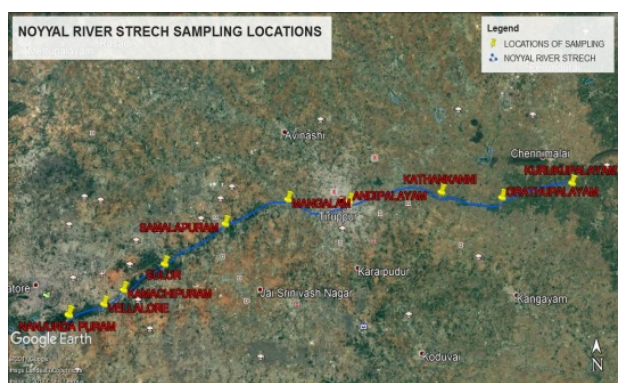

Fig. 1 Sampling Location of Noyyal River

\section{B. Overview of Wasp Modelling System}

WASP represents a complete re-design in the functionality and look and feel of the US EPA Water Quality Analysis Simulation Program (WASP). US EPA model base code is used in WASP model. The WASP system consists of two stand-alone computer programs which are DYNHYD5 and WASP. It can be run in conjunction and separately. The movement of water is simulated by the hydrodynamics program, DYNHYD5 while the movement and interaction of pollutants within the water are simulated by WASP. While DYNHYD5 is delivered with WASP, other hydrodynamic programs have also been linked with the WASP. The unsteady flow in the one-dimensional river is handled by RIVMOD, while unsteady, three-dimensional flow in lakes and estuaries are handled by SED3D (contact CEAM for availability).

While simulate two of the major classes of water quality problems WASP is supplied with two kinetic sub-models: conventional pollution (involving dissolved oxygen, biochemical oxygen demand, nutrients and eutrophication) and toxic pollution (involving organic chemicals, metals, and sediment). The linkage of either sub-model with the WASP program gives the models EUTRO and TOXI, respectively. The tracer block can be a dummy sub-model for substances with no kinetic interactions. In most instances, TOXI is used for tracers by specifying no decay.The conservation of mass is the basic principle of both the hydrodynamics and water-quality program. The tracked and accounted water volume and water-quality constituent masses are being studied for over time and space using a series of mass balancing equations. Conservation of momentum, or energy, throughout time and space are done by hydrodynamics program.

\section{Application of Wasp Software}

WASP model operation method is a river net first model to all turn, then carries on according to as follows 4 main steps: Water power studies, the quality deliver a research, fluid matter conversion research and environment poison the reason learn a research. Square one water power research wants to apply water power model procedure DYNHYD; Delivering of material in the second step research water current, depend show a drug research and the TOXI mold piece school of the fluid matter model procedure WASP check to complete; The third step research water current and the material conversion in the bottom quality, depend on laboratory research, the spot observation and experiment, parameter estimate, the model research combine together to complete, its model computes as a result want to verify; The end one step studies pollutant how influence environment [7].

\section{Implementation of the Model}

A set of expanded control volumes or segments are the model network that together represents the physical configuration of the water body. The network may subdivide the water body laterally and vertically as well as longitudinally. The steady-state data measured from March 2012 to September 2017 were used in assessing the water quality.

\section{E. Input Data}

The water quality data measured to assess the water quality of the river for September 2017 is given in Table II.

TABLE I SAMPLING LOCATION

\begin{tabular}{|l|c|c|}
\hline Location & Latitude & Longitude \\
\hline S1 & $11^{\circ} 1^{\prime} 58.00^{\prime \prime} \mathrm{N}$ & $7^{\circ} 6^{\prime} 56.81 " \mathrm{E}$ \\
\hline S2 & $11^{\circ} 4^{\prime} 43.14 " \mathrm{~N}$ & $7^{\circ} 11^{\prime} 30.73^{\prime \prime} \mathrm{E}$ \\
\hline S3 & $11^{\circ} 6^{\prime} 23.68^{\prime \prime} \mathrm{N}$ & $77^{\circ} 16^{\prime} 17.17^{\prime \prime} \mathrm{E}$ \\
\hline S4 & $11^{\circ} 6^{\prime} 14.28^{\prime \prime} \mathrm{N}$ & $77^{\circ} 20^{\prime} 52.99^{\prime \prime} \mathrm{E}$ \\
\hline S5 & $11^{\circ} 6^{\prime} 30.54 " \mathrm{~N}$ & $77^{\circ} 37^{\prime} 49.26^{\prime \prime} \mathrm{E}$ \\
\hline
\end{tabular}

TABLE II WATER QUALITY DATA FOR 2017

\begin{tabular}{|l|c|c|c|c|}
\hline Location & $\mathbf{p H}$ & $\begin{array}{c}\text { TDS } \\
(\mathbf{m g} / \mathbf{l})\end{array}$ & $\begin{array}{c}\text { DO } \\
(\mathbf{m g} / \mathbf{l})\end{array}$ & $\begin{array}{c}\mathbf{N O}_{3} \\
(\mathbf{m g} / \mathbf{l})\end{array}$ \\
\hline S1 & 7.16 & 856.6 & 4.3 & 4.7 \\
\hline S2 & 7.38 & 944.9 & 4.2 & 8.6 \\
\hline S3 & 7.51 & 1235.2 & 3.6 & 4.81 \\
\hline S4 & 7.77 & 1482.5 & 2.48 & 12.25 \\
\hline S5 & 7.61 & 1525.2 & 2.92 & 17.92 \\
\hline
\end{tabular}




\section{RESULTS AND DISCUSSION}

As stated above, the model is run for water quality parameters such as $\mathrm{pH}$, Total Dissolved Solids (TDS), Dissolved Oxygen (DO) and Nitrate $\left(\mathrm{NO}_{3}\right)$. The model was run based on average value of all spring months. Most of the river basins are withering in summer. The following graphs show the pollution level of the river at various locations. The $\mathrm{NO}_{3}$ is a measure of an indicator of other contaminants in water and it was observed that it was not exceeded the permissible limit (not greater than $45 \mathrm{mg} / \mathrm{l}$ ) from 2012 to 2017. But the high value (32 mg/l) is observed in the Orathupalayam dam segment due to sewage intrusion, effluents from the industries and domestic waste discharge into the river. The Dissolved Oxygen concentrations were predicted and it was found to exceed the permissible limit ( $>4 \mathrm{mg} / \mathrm{l}$ ). The lowest DO concentration was observed to be $2.2 \mathrm{mg} / \mathrm{l}$ at Orathupalayam dam segment, due to domestic sewage and insignificant point source.

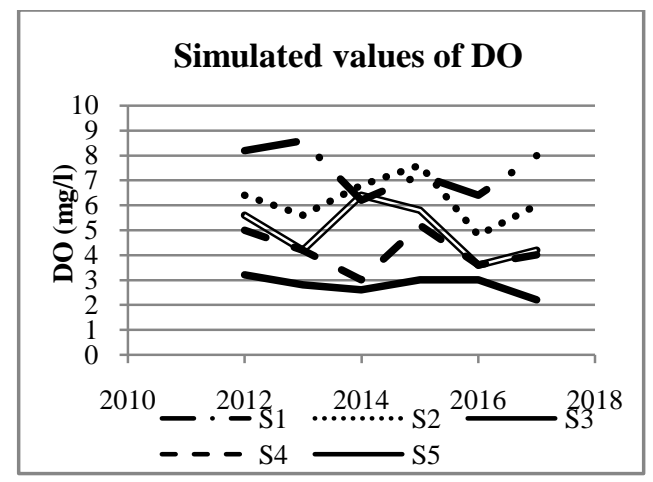

Fig. 2 Simulated values of DO

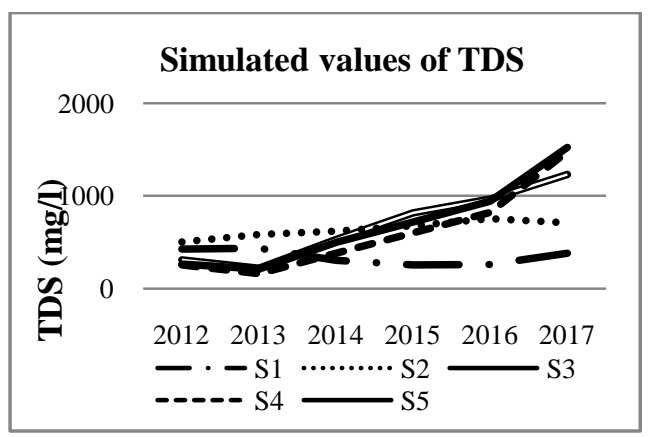

Fig. 3 Simulated values of TDS

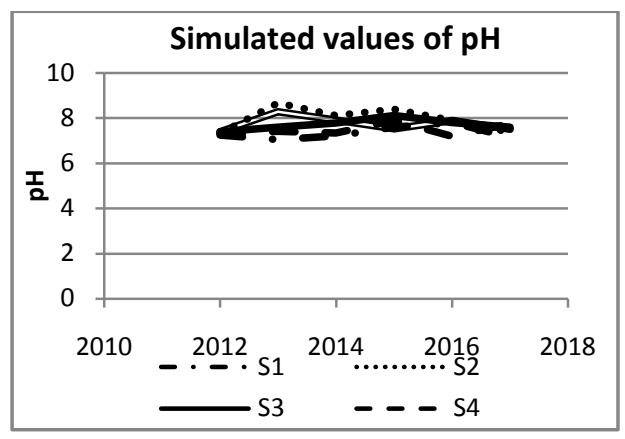

Fig. 4 Simulated values of $\mathrm{pH}$

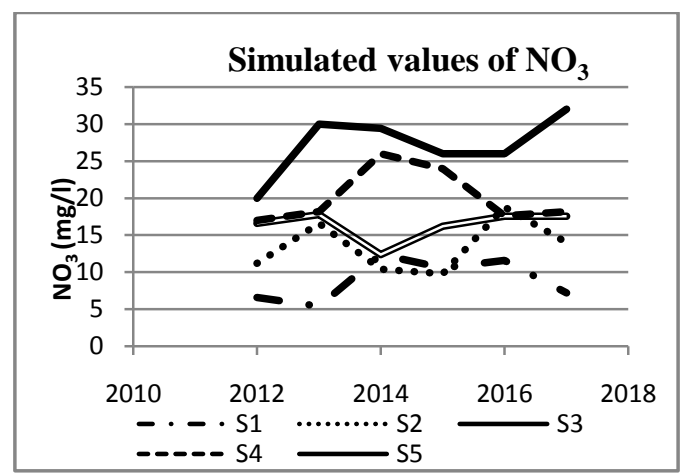

Fig. 5 Simulated values of $\mathrm{NO}_{3}$

Central pollution control board refers that river water is the best use for irrigation, industrial cooling and controlled waste disposal. The survival of aquatic habits is mainly based on $\mathrm{pH}$. The level of $\mathrm{pH}$ was found to be within the permissible limit (7.5-8.5) of 2012 to 2017. The dissolved solids are the concentrations of all dissolved minerals in water indicate the general nature of the salinity of the water. Due to industrial effluent and domestic waste discharges into river leads to high concentration of TDS in Orathupalayam dam segment. It was found to be $2245 \mathrm{mg} / \mathrm{l}$ which was exceeded the permissible limit (2000 mg/l).

\section{PERFORMANCE EVALUATION OF THE MODEL}

The model predicted the results were fairly good and the model performance was confirmed through evaluation of the results. Also the analysis of the simulated results was relatively in best agreement with the measured value. Model predictions of $\mathrm{NO}_{3}$ and $\mathrm{pH}$ fall within the measured bound of Sulur and Samalapuram segments. For all constituents, model prediction falls within the expected range of data nearly all measurement locations.

\section{CONCLUSION}

The present study characterized the quality of wastewater discharge into River Noyyal. Five segments were investigated along the river and their water quality characteristics were analyzed. In the data analysis at five segments along the river, water quality parameter such as $\mathrm{NO}_{3}$ and DO varied between $5.2 \mathrm{mg} / \mathrm{l}$ and $32 \mathrm{mg} / \mathrm{l}$ and 2.2 $\mathrm{mg} / \mathrm{l}$ and $8.6 \mathrm{mg} / \mathrm{l}$, respectively for 2017. The obtained results will be very useful to implementing policies and solutions for improving the water quality in the river Noyyal up to the required level. This study found that the model results were compared with the model input parameters. WASP clearly has potential for assessing water quality along the river and could be implemented as a valuable tool to inform Noyyal River management.

\section{REMEDIAL MEASURES}

1. Industrial and domestic effluents may be fully treated and disinfected before discharging into river. 
2. Identifying the effluent from non-point source and these are required to be collected and treated.

\section{REFERENCES}

[1] S. Mariraj Mohan and P. Vanalakshmi, "Assessment of Water Quality in Noyyal River through Water Quality Index", International Journal of Water Resources and Environmental Engineering, Vol. 5, No. 1, pp. 35-48, Jan. 2013.

[2] A. Samuel Rajkumar and S. Nagan, "Study on Tiruppur CETPs discharge and their impact on Noyyal River and Orathupalayam dam, Tamil Nadu, (India)", Journal of Environmental Research And Development, Vol. 5, No. 3, Jan-March 2011.

[3] M.Vasudevan, I. M.Nambi and G. Suresh Kumar", Application of Qual2k for Assessing Waste Loading Scenario in River Yamuna", International Journal of Advanced Engineering Technology, Vol. 22, pp. 336-344, 2011.

[4] YV Jain and Chetan Singh, "Pollution in Yamuna River", Journal of Water and Environmental Engineering, Vol. 6, No. 2, pp. 556-562, 2012.

[5] RituPaliwal and Prateek Sharma, "Application of Qual2E for the River Yamuna to Assess the Impact of Point Loads and to Recommend Measures to Improve Water Quality of the River”, Centre for Regulatory and Policy Research, TERI School of Advanced Studies, New Delhi, India, 2002.

[6] R. Babunath and G. John, "A Study on Physico Chemical and Heavy Metals Characteristics of River Noyyal, Tamil Nadu, India”, Vol. 13, Issue 1, 27 Feb. 2017.
[7] Tim A. Wool, "Water Quality Simulation Program, (WASP) user’s manual".

[8] Y. A. Abdu, "Implementation of Lean Manufacturing: A Case Study at ASK Automotive Private Limited (India)", International Journal of Advanced Research in Science, and Technology, Vol. 5, No.1, pp. 556-562, 2016.

[9] H. DurmishiBujar, I. Murtezan andS. Agim, "The physical, physicalchemical and chemical parameters determination of river water Shkumbini (Pena), Balwois - Ohrid”, Republic of Macedonia,Vol. 1, 27, 31 May 2008.

[10] Mohammad MotiurRahman, NaheenaHaq and Rashedur M Rahman "Comparative Study of Forecasting Models on Clustered Region of Bangladesh to Predict Rice Yield”, 17th IEEE Int. Conf. on Computer and Information Technology (ICCIT), Dhaka, 2014.

[11] S. Samson and K. Elangovan, "Assessment of ground Water Quality for Drinking Purposes in Namakkal District Tamil Nadu, India", Pollution Research, 2011.

[12] A. H. Schumann,"Development of Conceptual Semi-Distributed Hydrological Models and Estimation of their Parameters with the aid of GIS”, J Hydrol Sci. 38:519528, 1993.

[13] N. C. Ghosh andE. A. Mcbean, "Water Quality Modeling of the Kali River, India”, Water, Air \& Soil Pollution, Vol. 102, pp. 91-103, 1998.

[14] P. R. Kennel, S. Lee, S. R.Kanel, Y. Lee and K. H. Ahn, “Application of QUAL2Kw for water quality modeling and dissolved oxygen control in the river Bagmati”, Environtal Monitoring Assessment, Vol. 125, pp. 201-217, 2007.

[15] M. Campolo, P. Andreussi and A. Soldati, "Water Quality Control in the River Arno, Technical Note”, Water Research,Vol. 36, pp. 26732680, 2002. 